\title{
Individual Decision-making Model of Institutional Change*
}

\author{
Xiaoyan Lv \\ Xi'an FanYi University \\ Xi'an, China
}

\begin{abstract}
The mainstream new institutional economists takes transaction costs as the core to analyze the evolution of the economic system from equilibrium to non-equilibrium to a new equilibrium, namely the process of institutional change. This kind of analytical framework relies too much on the concept of transaction costs. Due to the inherent problems in the concept of transaction costs, this theoretical framework is not perfect. However, through a detailed analysis of the issues involved in this framework analysis process, key variables such as subject rationality, interest structure, resource constraints, technical constraints, and institutional constraints can be abstracted. Based on these variables, a new integrated model of individual decision-making in institutional change can be constructed preliminarily.
\end{abstract}

Keywords - transaction cost; institutional change; individual decision model

\section{INTRODUCTION}

Any theory must have its basic concept system. The analysis of the basic concepts constitutes one of the main parts of the theory, and then the relationship between these concepts is explained, so that the initial construction of the theoretical system can be completed. Institution is one of the variables of model equilibrium, which is not only the initial constraint condition of subject behavior, but also the result of subject behavior under external impact. However, we don't know whether it is the result of the subject's intention or the result of the subject's unintentional behavior.

\section{ANALYTICAL FRAMEWORK OF TRANSACTION COST OF INSTITUTIONAL CHANGES}

\section{A. Transaction Costs and Institutional Equilibrium}

When the transaction cost reaches a certain level, it is profitable to set up a company and conduct market transactions within the company. Therefore, the saving of transaction cost is the reason for the company's production, and when the market and the company's transaction costs on the margin reach equilibrium, the border of the company has also been determined. If transaction cost is zero, no matter

*Fund Project: Research Project of Shaanxi Provincial Department of Education "Research on the Protection and Development of the Zhongnan Folk Culture Industry” (No. 17JK0987), School-level scientific research team construction project of Xi'an FanYi University "The Development of the Regional Economy and Industry" (No. XFU17KYTDC02) how the property rights are defined, it will not affect the efficiency of resource allocation. However, if the transaction costs are positive, different property rights delimitation will have a decisive influence on the effective allocation of resources. Simply considering the transaction cost is insufficient, so the new institutional economist, on the basis of the transaction cost, introduces the transaction return variable and the transaction net return variable, i.e. profit, to analyze the institutional changes. The analytical framework for institutional change with transaction costs, trading returns and trading profits or transaction efficiency as the core variable can easily define an institutional equilibrium state, and the system will have a dynamic equilibrium or stable state, i.e., behavioral equilibrium.

\section{B. Institutional Disequilibrium and Institutional Changes}

The impact of the external environment and the internal conflicts of the institution lead to the institutional disequilibrium. The "potential profit" encourages institutional innovation by institutional entities, resulting in institutional changes. The main body of the system makes the institution achieve a new state of institutional equilibrium in order to pursue the potential profits caused by the institutional disequilibrium. The repetition of this process constitutes institutional changes.

\section{Analytical Framework of Supply and Demand of Institutional Changes}

The analysis of supply and demand for institutional change is the improvement and development of the analytical framework for transaction costs of institutional changes on the basis of comparison of transaction costs and transaction revenue. The analysis of supply and demand of the system is based on the analysis of institutional costs and institutional benefits. Only if the benefits of system supply and demand outweigh the costs, can it be possible to realize the effective supply and effective demand of the system and thus realize the institutional changes. For the further improvement of the analytical framework for the supply and demand of institutional changes, there are two main ideas. The first is to analyze the significant influence of the past institutional structure on the current and future institutional structure from the perspective of time. The advancement along this line of thought requires a slow progress in the detailed analysis of the continuous transition of the system on the time axis. Another thought is to analyze the 
significance of institutional structural contradiction on institutional changes from the perspective of space. In the analysis of the marginal evolution of institutional changes, North emphasizes the influence of changes of informal rules on the margin of formal rules to the formal rules. In fact, the adjustment of formal rules on the margin also brings about the marginal adjustment of inform rule and thus affect institutional changes. On the one hand, it is to explain that the system is a process from quantitative change to a qualitative change beginning from the marginal or partial adjustment. On the other hand, it also opens up the way of analyzing institutional changes from the perspective of institutional structure. It can be seen that institutional change is a process of marginal evolution in both time and space.

\section{The Micro-dynamics of the Analysis of Institutional Changes in Transaction Costs}

The system is essentially a "contract form" between people. This relationship can be regarded as a property right relationship from another perspective. In fact, the entire analytical framework for institutional changes centering on transaction costs is based on maximization of the interests of economic entities themselves. The macro analysis of the theory of institutional change now gradually transitions from a supply-demand analysis, path-dependent analysis, and institutional structure analysis of institutional changes to microscopic analysis. The behavior of economic entities pursuing the maximization of their interests will automatically lead to effective changes in the entire social system. Micro-analysis of institutional changes studies how to maximize the decision-making of individual interests, and gradually derives the changes of the entire social system. Research in this area has two basic traditions: one is rational constructionism of institutional change, and the other is the spontaneous evolution of institutional change. The behavior of maximizing the self-interest of economic individuals is the ultimate power or micro-power of institutional change.

\section{INDIVIDUAL DECISION VARIABLES DESIGN OF THE INSTITUTIONAL CHANGE}

Any theory must have its basic concept system. The analysis of the basic concepts constitutes one of the main parts of the theory, and then the relationship between these concepts is explained. Thus preliminary construction of the theoretical system can be completed. From the series of documents on institutional changes, the author summarizes the basic variables that affect institutional changes, and uses these variables as a basis to complete the preliminary design of a microscopic model of institutional change.

\section{A. Economic Entities in Institutional Changes}

As a kind of relationship between people, the dynamic process of institutional change necessarily involves the subject issue of institutional change. The main body of institutional change is sometimes a single economic person, sometimes a family or organization, and sometimes a government or international agency. Different subject analysis produces different analysis theories of institutional change. For example, the simple addition of individual actions is not a collective action, but the behavior of a family or an organization has different characteristics of many individuals acting together. The coercive government institutional behavior is more different from the institutional behavior of an unprivileged individual or organization.

\section{B. The Interest Structure of Subjects in the Institutional Changes}

This factor stems from the assumption that any economic entity pursues the maximization of its own interests and has inexhaustible desires, so each subject has its own unique interest structure, and different economic entities have different economic interests, but there is a certain degree of common interest. Although classical and neoclassical economics both believe that economic entities pursues the maximization of their own interests, all of them have abstracted all economic subjects into a single rational economic man with no difference in interest structure. Although game theory emphasizes that the interest structures of different economic entities are different, it only analyze the different consequences, namely cooperation and competition. Rational institutionalism of institutional change in the new institutional economists although accepts the significance of the behavior of maximizing the interest of the subjects to institutional change, and emphasizes that different economic entities are different, the emphasis on the interest structure is still insufficient. In most cases, people subconsciously apply the important variable of interest structure, but the emphasis and attention are not sufficient.

\section{Subjective Rationality in Institutional Changes}

The rational question is the key factor for the emergence of neoinstitutional economics. Neoinstitutional economists criticizes that neoclassical theory regards the economic subject as completely rational, and considered that the economic subject is limited rationality. However, the decision-making environment of the economic subject is indefinite, so the decision information is incomplete and asymmetric. Therefore, in order to make up for limited rationality, reduce the uncertainty, and obtain sufficient information, it is inevitable for economic entities to take the transaction costs of corresponding actions, thus introducing the institutional analysis. The economic subject is indeed limited rationality, which often serves as the reason for some economists to think that institutional change cannot be rational chosen by economic subject and institutional change is a reason for the spontaneous evolution process. There is no doubt that the rationality of the economic subject has an important influence on the behavior of the economic subject, and thus plays an important role in the institutional change. Although the exact definition of rationality is extremely difficult, but a rough examination can find that rationality is related to the knowledge, habits, will, and psychological factors of economic subjects. The analysis of this aspect, especially the role of knowledge in institutional changes, is paid great attention by economics, especially the evolutionists of some institutional changes, such as Hayek who emphasizes the importance of knowledge structure and knowledge distribution to institutional changes. 


\section{Resource Constraints Faced by Economic Entities in Institutional Changes}

Both rational constructionists of institutional change and spontaneous evolutionist of institutional change all admit that the change and operation of the institution is a matter that extremely consumes economic resources. That is to say, the establishment, operation, and transition of the institution all have transaction costs. In a particular economic system, the accumulation and distribution of resources fundamentally determine the means, methods and direction of institutional changes in this economic system. The importance of resources comes from the fact that resources are always limited to people's unlimited desires and needs. It is overstated to describe the entire historical process of mankind as the history of resource race. The continuous expansion and extension of human needs, the continuous reduction of the original resources, and the discovery of new resources may all directly lead to the disappearance, emergence, or change of a certain institution. One of the factors that are closely related to the resource variables is technical factor. Due to technical limitations, people often cannot find certain important resources or cannot use them, resulting in the inability of emergence of certain important institution. The advancement of technology on the one hand makes it possible for people to use and fight for more resources. On the other hand, technology is also very important for the establishment, operation and change of institution because the establishment of certain institution must also be based on the existence and advancement of certain technologies. Another variable closely related to resources and technology is the development of profession and division of labor. In the age of Adam Smith, the importance of specialization and division of labor for improving economic efficiency has been attached great importance. It is believed that specialization and division of labor increase the level of technology, promote the accumulation of knowledge, expand the scope of transactions and markets, and promote economic growth. An important factor associated with specialization and division of labor is the decomposition, reorganization, and innovation of different property rights based on property rights of the same property. This is considered by some economists to be an important cause of institutional creation, innovation, and change. However, as for the decomposition, reorganization, and innovation of property rights, there is also a key variable that has been neglected. That means any property rights are based on specific property or resources. The existence of specific resources is an important basis for people's property rights to these resources and the economic relationship between people based on these property rights, which shows the importance of resources to the system and its changes.

\section{E. The System Itself Constitutes an Important Constraint on the Behavior of Economic Entities}

From the perspective of subject behavior constraints, analyzing the behavior of economic entities pursuing the maximization of their own interests can find that institutions play the restrictive roles for the behaviors of subjects. Economists define the institution as the rule of behavior, and believe that the system defines the space for the behavior choice of economic entities, and gives the corresponding incentives to the economic entities. The important meaning of the institution itself for institutional change comes from two aspects, one is the path dependence of institutional change, and the other is that any institutional change is a structural change process. That is to say, within a certain institutional framework, the change of a specific institutional arrangement affects other changes in specific institutional arrangements. As a result, institutional changes gradually accumulate in quantitative changes and once the critical point is reached, the entire institution will change.

\section{F. Historical Dependence of Economic System Changes and Nonlinearity of Impact}

The change of any variable depends not only on the change of other variables related to this period, but also on past values of other variables. This view can be regarded as the path dependency of variable, where the path dependency of variable is more complex and general than the path dependency we often refer to in institutional change. A relationship corresponding to the path dependence of a variable is the non-linear relationship between variables, which means that the effect of variable $A$ on variable $C$ can be either acted directly on $\mathrm{C}$ by $\mathrm{A}$ or indirectly acted on $\mathrm{C}$ through B. Of course, the process and relationship in it can be even more complicated. In reality, such non-linear relationships include team production, principal-agent relations, moral hazard, adverse selection, and even hitchhiking.

\section{THE INDIVIDUAL DECISION-MAKING MODEL OF INSTITUTIONAL CHANGE}

\section{A. A Simple Description of the Model}

This model can be simply described as: supposing that there are countless economic entities in the economic system and that they are all homogeneous, then any economic entity takes corresponding actions under certain constraints to pursue the maximization of their own interests. The behavior of pursuing the maximization of self-interest will in turn lead to changes in the constraints that he faces, and then change the space in which the economic entity pursues the maximization of interests, and ultimately motivate the economic entity to pursue further and greater benefits under the new constraints, which in turn have led to further changes in the constraints, thus repeating the circle.

\section{B. The Initial Environment of the Behavior of Economic Entities}

The motivation of the economic entities pursuing the maximization of interest comes from an impact outside the model system. The original equilibrium state has been changed. However, the first is the change of the subject's behavioral constraints, and then the change of the incentive, and finally the change of the subject's behavior.

If the external shock is continuous, the cycle between the behavior and constraint condition of the economic individual's pursuing the maximization of interest will not be 
terminated; if the external shock is relatively slow or less, the constraints of the economic individual's behavior change less, and changes in constraints through incentives of maximizing the behavior of the benefits will be slow and less frequent. If the external total impact is diversified, complex, and hierarchical, and the impacts are intertwined, there is no strict order between the economic entities' pursuit of the maximization of their own interests and the constraints of their behavior. Instead, they work together through intertwining of diversification, complexity and hierarchy.

It can be seen that the starting point of the analysis is a balanced state. Since the imbalance of variables inevitably leads to unbalanced behavior, setting this equilibrium state includes both variable equilibrium and behavioral equilibrium. The meaning of equilibrium includes the equilibrium state among the different constraints within the subject's behavioral constraints, the behavior constraints faced by the economic entities and equilibrium state among the behaviors, and no external shock existing in the economic institution. The behavioral constraints of economic entities in this model include the subjective rationality level, subject interest structure, subjective resource endowment, subjective technology level, and subjective institutional structure. When there is no external shock, the behavior of subject pursuing the maximization of self-interest will ultimately lead to a static equilibrium between the subject's behavior and the constraints and the constraints themselves.

\section{The Meaning of Subjectivity or Non-subjectivity}

Both the spontaneous evolutionary analysis of institutional changes and the traditional analysis of the rational construction of institutional changes acknowledge that institutional change as a social relationship or the relationship between people is necessarily the result of human behavior. The difference is that when human beings take actions to achieve a specific purpose, the object of his action is the result of their intentional choice, and the result of this behavior is also the purpose of this action. Besides, the subject is aware of the freedom to take action. Subjectivity refers to the correspondence between the following variables. If it exists, it indicates that the result has subjectivity; otherwise, behavior and result do not exist. That is, case 1: Subject A's A behavior is taken to achieve A result, so A result emerges due to A's A behavior; case 2: Although Subject A's behavior $A$ is to achieve result $A$, result $A$ is achieved because of the behavior B of subject A; case 3: The behavior $\mathrm{A}$ of the subject $\mathrm{A}$ in order to achieve the result $\mathrm{A}$ leads to the result $\mathrm{B}$. The result $\mathrm{A}$ in the above case 1 can be called the product constructed by subjective rationality, while the result $A$ and result $B$ in case 2 and case 3 are not the product constructed by subjective rationality. If the result $\mathrm{C}$ is not a direct object of any behavior of any subject, but the result $\mathrm{C}$ is still produced, we can only say that the result $\mathrm{C}$ is the product of the spontaneous evolution of the economic system associated with $\mathrm{C}$.

\section{The Way of the Institution Changes}

The ultimate result of the subject's behavior is to maximize the self-interest, but any interest must be realized by means of certain tools. Therefore, the object that the subject directly acts on can only become the means and tool through which the subject realizes its own interests. From this perspective, the subject's interest structure is an important variable that corresponds to the decision variables of other entities. Economic entities use other decision variables as tools in order to realize their own interest structure. When the institution becomes an important tool for the subject to realize its own interests, it will inevitably become the direct object and direct target of the subject's behavior. When an external shock occurs, it will inevitably lead to the destruction of the original equilibrium and the subject must take new actions. First, the external shock directly leads to the change of the subject's interest structure, but this interest structure cannot be realized in the original constraint conditions, which inevitably leads to behavioral incentives that change the original behavioral tools in pursuit of greater interests; second, external shocks lead to changes in all or part of the original constraints, and changes in constraints will inevitably change the potential maximum interests of economic entities, and ultimately motivate economic entities to take new behavior. This new behavior will inevitably lead to changes in the original constraints. External shocks bring about changes in the structure of potential interests of the entity and encourage economic entities to adopt new tools to realize these potential benefits. As a result, the system changes as one of the tools.

\section{CONCLUSION}

The institution is one of the variables of the model equilibrium, which is not only the initial constraint of the subject's behavior but also the result of the subject's behavior under the external shock. However, we don't know whether it is the result of the subject's intention or the result of the subject's unintended behavior. Perhaps what's important is not the debate between these two traditions, but the details of the process that institutions, groups, organizations, or groups are produced when we assume that there are two heterogeneous economic entities in the world or multiple heterogeneous economic entities. Here, the application of game theory in institutional analysis may be an optimal tool, and research in this direction has achieved tremendous success. Although the game theory analysis method began around the middle of the 20th century, the earliest analysis of the institutional phenomenon from the perspective of game theory was made by the American economist Andrew Schott in the book "Economic Theory" by Cambridge University Press in 1981. In the book, Professor Schott tried to use the game model to show people the details of the institutional evolution theory of Smith-Megger-Hajek-Nozick, and other economists such as H. Peiton Yang and Aoki Harihiko have done a lot of work in this direction. The review of this direction modeling remains to be further studied.

\section{REFERENCES}

[1] Douglas North. Institution, Institutional Change, and Economic Performance [M]. Shanghai People's Publishing House, 1994. 
[2] Sheng Hong. Modern Institutional Economics (Volume Two). Peking University Press [M], 2003.

[3] Ronald Coase. Nature of the Firm [M], 2003.

[4] Wesson. Economics and Philosophy - The Philosophical Basis of Institutional Analysis [M]. Shanghai People's Publishing House, 2005.

[5] Wang Dingding. From transaction costs to game equilibrium [M]. Peking University Press, 2003.

[6] Zhang Shuguang. On Institutional Equilibrium and Institutional Change [M], 2003. 